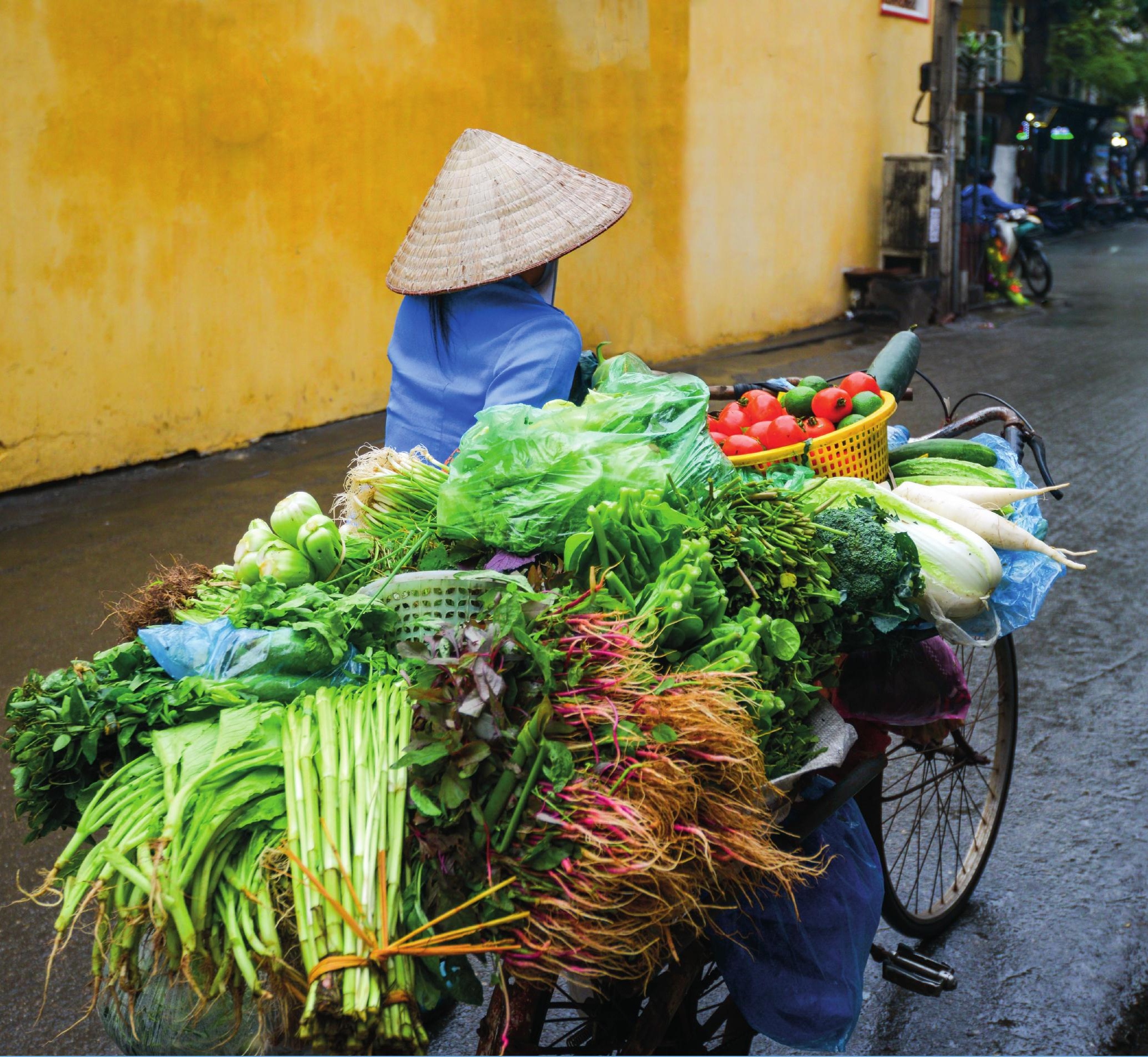

\title{
An Introduction to Food Systems Thinking
}

How Members of Multi-Stakeholder Platforms in Vietnam Can Apply Food

Systems Thinking in Practice

Katherine Pittore and Tran Hai

Alliance

WAGENINGEN

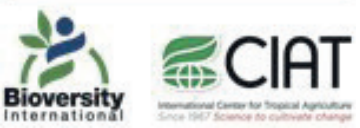

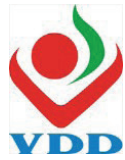





\section{An Introduction to Food Systems Thinking}

How Members of Multi-Stakeholder Platforms in Vietnam Can Apply Food Systems Thinking in Practice

Katherine Pittore and Tran Hai

This research was funded by The International Food Policy Research Institute (IFPRI) programme on Food System for Healthier Diets (FSHD), part of the IFPRI-led Agriculture for Nutrition and Health (A4NH) phase II (2017 - 2022) (project number 8141708305).

Wageningen Centre for Development Innovation

Wageningen, November 2021 
Katherine Pittore and Tran Hai, 2021. An Introduction to Food Systems Thinking; How Members of Multi-Stakeholder Platforms in Vietnam Can Apply Food Systems Thinking in Practice. Wageningen Centre for Development Innovation, Wageningen University \& Research. Report WCDI-21-183. Wageningen.

This report presents the findings from a two day online Food Systems Training with member of Multistakeholder Platfroms active in Vietnam carried out in October 2021. The workshop was organized by Wageningen Centre for Development Innovation, CIAT and the Vietnamese National Institute of Nutrition (NIN). The workshop was based on tools from the Food Systems Decision Support Tool Developed by KIT, the Netherlands Food Partnership and Wageningen University. The first part of the report presents finds from the workshop, the second reflects on the Food Systems Decision Support Tool.

Keywords: Multi-stakeholder Platforms, Vietnam, healthy diets, food systems, Food System Decision Support Tool

This report can be downloaded for free at https://doi.org/10.18174/556933 or at www.wur.eu/cdi (under publications).

(C) 2021 Wageningen Centre for Development Innovation, part of the Stichting Wageningen Research. P.O. Box 88, 6700 AB Wageningen, The Netherlands. T + 31 (0)317 4868 00, E info.cdi@wur.nl, www.wur.eu/cdi.

\section{(cc) BY-NC}

The Wageningen Centre for Development Innovation uses a Creative Commons Attribution 4.0 (Netherlands) licence for its reports.

The user may copy, distribute and transmit the work and create derivative works. Third-party material that has been used in the work and to which intellectual property rights apply may not be used without prior permission of the third party concerned. The user must specify the name as stated by the author or licence holder of the work, but not in such a way as to give the impression that the work of the user or the way in which the work has been used are being endorsed. The user may not use this work for commercial purposes.

The Wageningen Centre for Development Innovation accepts no liability for any damage arising from the use of the results of this research or the application of the recommendations.

Report WCDI-21-183

Photo cover: Shutterstock 


\section{Contents}

Background

Vietnam Training

Key findings from the Workshop

8

Day 1: Mapping The Vietnamese Food System

8

Day 2: The Iceberg Model

Reflections on Food System Decision Support Tool

References 



\section{Background}

Over the last five years Wageningen Centre for Development Innovation has been exploring the role that Multi-Stakeholder Platforms (MSPs) can play in supporting countries in food system transitions which places healthy diets at the centre, as part of the Platforms for Healthier Diets project. This work was carried out as part of the Flagship on Food Systems for Healthier Diets (FS4HD) is one of the programs of the IFPRI-led CGIAR Agriculture for Nutrition and Health (A4NH) project. The project focuses on four countries: Bangladesh, Ethiopia, Nigeria and Vietnam.

The platforms for Healthier Diets project began with conceptualizing the idea of multi-stakeholder platforms, as well as healthier diets, and identification of a set of criteria that could be used to map multi-stakeholder platforms in the four A4NH countries. This work was followed by a desk based mapping of all the platforms that met the criteria for multi stakeholder platforms working healthier diets (broadly defined). The results of this mapping were shared with stakeholders in Vietnam, Nigeria, and Bangladesh, who reflected on the research findings. Finally, we explored how we could support countries to embed and scale ideas of healthy diets as a central goal of the food system, by considering the key policy priorities of each country and how platforms engage with these policies, for example by supporting with agenda setting or policy implementation.

We found that in many countries, policies are looking more holistically at the food system compared to MSPs which tend to have a narrow focus, for example looking at the urgency around tackling high levels of malnutrition or scaling up specific types of agricultural interventions. At the time the scans were carried out, we did not find any multi-stakeholder platforms in the four A4NH countries that are working on food systems explicitly. However, while this is not currently happening, we believe MSPS may hold real potential for supporting effective food systems governance, and the transition to food systems which support healthy diets for all citizens.

Herens et al. (forthcoming) suggested MSPs could support food systems transformations, but the ability of MSPs to span boundaries between food systems actors needs to be strengthened, including by building capacity at the individual, institutional or organizational level. The training on food systems held in Vietnam was an initial start to supporting the improved capacity of MSPs to support a food Systems based framing, and to pilot potential tools to increase food system knowledge, that can be used with other MSPs in other context.

In the past few years, more and more materials have come available to support platforms, organizations and individuals to better incorporate food systems thinking in their work. However, As many of these tools are quite new, there has been less opportunity to pilot then with practitioners, and adjust to make them more user friendly.

This report is structured in two parts. The first part presents key findings from a two day online training "An Introduction to Food Systems Thinking: How Members of Multi-Stakeholder Platforms in Vietnam Can Apply Food Systems Thinking in Practice". The second section presents an overall reflection on the food systems decision support tool and suggestions for how this tool could be further strengthened. 


\section{Vietnam Training}

The goal of the workshop in Vietnam was to introduce members of Vietnamese multi-stakeholder platforms to food Systems thinking, by using a number of tools from the Food System Decision Support Toolkit, to better understand the Vietnamese food system. Following the workshop, participants filled in reflections on the tools and their utility for improving their understanding of a food system.

The workshop was organized online, on the $20^{\text {th }}$ and $21^{\text {st }}$ of October 2021 and was co-costed by Wageningen University and Research, CIAT, and the Vietnamese National Institute for Nutrition (NIN). A total of 43 individuals participated in the workshop, from a range of sectors. The majority of participants came from nongovernmental organizations, and government.

On the first day of the workshop, the concept of food systems was introduced, and key principles of food systems thinking were shared with the group. This session focused on the three quality principles necessary for a food systems analysis: system thinking, stakeholder involvement, and equity and inclusiveness (Posthumus et al. 2021). Dr Doa The Anh Vien Presented new work and priorities of the Vietnamese government, including how the new nutrition policy incorporates food system thinking. He stressed the need to focus on issues of interconnectedness and highlighted a number of key priority areas including increasing food systems reliance, improving connections between actors and establishing networks to increase innovation. His presentation was followed by an interactive activity in which participants selected one key outcome of interest, and mapped activities along the food system leading to this outcomes. This allowed participants to develop a broad understanding of key challenges in the Vietnamese food system and their interlinkages.

In the second day, the focus shifted from a broad mapping to a deeper dive into one of the key issues using the iceberg model, in which participants are stimulated to think about the underlying causes to an event that is visible above the surface, but which is caused by many less visible factors. The final session considered where the various actors present at the workshop are active in the food system, and reflected on how multi-stakeholder platforms could support the shift to a more systems based understanding of the food system.

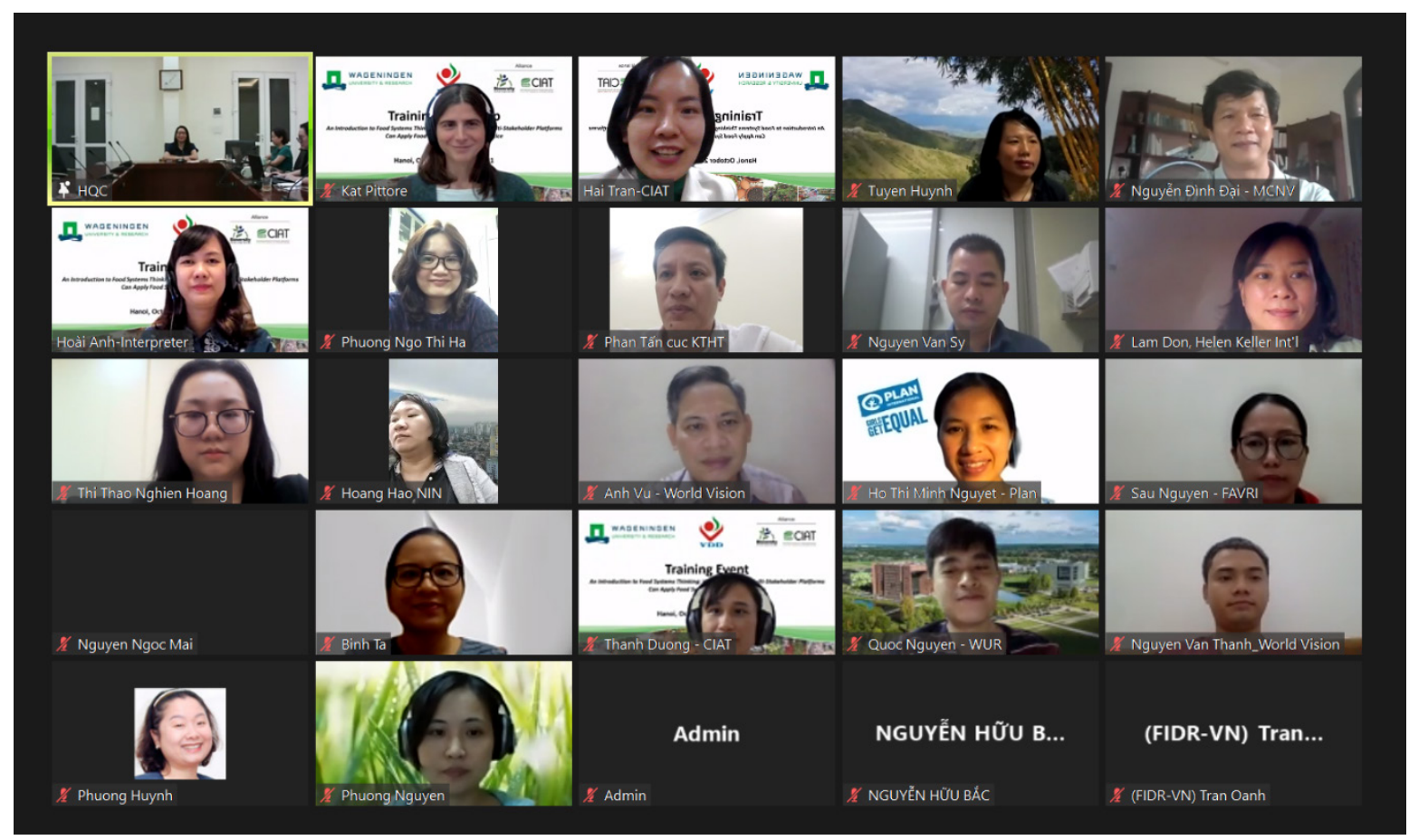




\section{Key findings from the Workshop}

\section{Day 1: Mapping The Vietnamese Food System}

Participants were divided equally into three groups. Two groups focused on the issues of healthy and safe foods, specifically for people in mountain regions in Northern Vietnam. The third group focused on production and challenges of policy implementation.

Critical food system issues identified included:

Agricultural Production: low agricultural production especially of local traditional foods which grow well in the mountainous areas, limitted knowledge of improved agricultural production techniques and challenges in accessing new agricultural technologies.

Storage, transportation and trade: limitted market access, manufactures and distributors do not prioritize the mountainous north due to poor roads and low consumer purchasing power; challenges of transportation made worse during COVID with limits to movement; export market affects people's ability to access safe and healthy food domestically.

Food processing and transformation: manufactures do not prioritize food safety and often use unsafe food preservation methods.

Food Retail and provision: many small retailors cannot comply with labeling regulations, especially in rural areas. Consumers in mountainous areas have a preference for familiar, local food and may not accept new foods provided by retailers.

Food consumption: limitted consumer awareness, especially regarding the low nutritional value of ultra-processed foods, exacerbated by misleading advertising and marketing, few policies limiting promotion of ultra-processed foods; limited access to household level food preservation (few own refrigerators in Northern mountain areas); low purchasing power means people cannot afford healthy foods; healthier foods are more expensive; Community preference for seasonable and local foods means even when other foods are available consumers may choose not to purchase them.

Socio-economic drivers: gender issues including women's inability to ride a motorbike limit their ability to travel to the market; high cost of transportation of process foods to mountainous areas is not economically advantageous to retailors, exacerbated during COVID.

Environmental drivers: climate change has led to a longer rainy season, which impacts growing season and effects overall agricultural productivity. 


\section{Day 2: The Iceberg Model}

In the second day of the workshop, we used the iceberg model to dive more deeply into one of the critical problems that was mentioned in day 1 and look at the underlying system causalities. The idea is that these can be used to identify leverage points for systems change. However, in the short space of the workshop, we did not have time to go into potential leverage points for change.

\section{Group 1}

In the first day's analysis, one of groups mentioned an interesting example from the mountainous areas in the North, an area with many indigenous groups, high levels of poverty and much higher rater of undernutrition than in the rest of Vietnam. One key challenge is that there are few markets and people have limited market access, as the markets happen irregularly. The Government proposed a solution to tackle this challenge by building a permeant market. However, the market is not used by the people and the challenges it was designed to address continue.

Event: people do not use the new market built by the government to support year round access to fresh foods for people in mountain areas.

Patterns: people do not trust the products for sale and they find the market too expensive. People see no advantage of coming to the new market to buy the similar or the same food which they can buy traditional market where everyone come then sell their products without any regulations regarding food safety. People do not want to travel long distance to the new market.

Structures: Because the market is ongoing, they have to change high fees and taxes, making products more expensive than the seasonal markets where they usually shop. High transport costs to travel to the market also mean people are less likely to shop there.

Mental models: There are policies supporting relators to sell foods on the market, as well as a board to help manage the market; however there is a not enough budget to support the implementation of these policies. Additional policies could address some of the structures that limit people's access to the market, for example introducing a policy to subsidize travel to the market or support activities to raise the profile of the market and stimulate consumer demand. This could be a role of the market board, but would also require additional budget which is not currently available.

\section{Group 2}

The issue of equity and inclusiveness came out strongly in the first day's discussion, especially as many of the workshop participants come from NGOs who specifically focus on the most disadvantaged in society.

Event: safe, healthy food is not available for all consumers groups in all geographies.

Patters: Safe and healthy foods are only available for wealthy urban consumers but not poor rural consumers. Those with limited purchasing power focus on enough food for their families, rather than enough safe foods. Agricultural productivity is too low to ensure healthy foods are available for all at affordable prices.

Structures: the issue of trust at all levels (growers, producers, retailors and consumers) came out strongly. Even with certification schemes, people do not trust supermarkets and prefer to purchase foods from a relator they have an established relationship. Small holder farmers cannot access modern agricultural technologies.

Mental models: levels of trust need to be built at all levels of the food system, for example supporting systems to allow for improved tractability, community monitoring of food systems and/or improved support to small and medium sized companies to support improved monitoring. 


\section{Group 3}

Focused on the challenge producers face in accessing technology for sustainable production of safe and healthy foods.

Event: Producers cannot access necessary technology for the sustainable production.

Patters: Some farmers know about new technologies but they cannot access them (are not available or affordable) and some do not know about the services.

Structures: There are limitations to policy implementation (e.g. support to improve synergy and policy coordination), individuals are constrained by actions of neighbors (e.g. organic production). There are also tensions between policies, for example those designed to prevent food waste and those related to food safety.

Mental models: The underlying models are reinforced throughout the food systems, consumers do not demand more sustainably produced foods, or they prefer traditional ways of doing things and do not willing to change (example of resistance to fortifying processed foods, despite new government regulations). From the policy side, there is a need for more activities to raise consumer awarenss about nutrition, as well as policies to support farmers to adopt new technologies. Individual farmers could come together in cooperatives to more easily access modern technologies.

Engaging Multi-stakeholder Platforms in Food Systems: In the final session, participants reflected on how various multi-stakeholder platforms might use these tools. Similar to when we had the validation workshop, there was a challenge in translation, as the Vietnamese language has no word for platform. Participants were interested to continue to work with each other and hoped that the training could serve as a way to build longer term collaborations. 


\section{Reflections on Food System Decision Support Tool}

In general, the participants valued the tools and training. Based on a post-course survey with 40 respondents, $93 \%$ of participants said that there understanding of food systems improved a lot or significantly as a result of the training and $88 \%$ reporting that they will be able to apply what they learned in the training to their own work.

However, there are also a few suggestions of how to how the Food Systems Decision Support Tool could be made more practical. While there are various levels of analysis offered in the guide, from awareness raising, to exploration, to analytic tools, many of these tools are already quite in depth and miss an overall introduction to the food system and the idea of system thinking more broadly. In the A4NH Platform mapping work, we have developed an activity where participants use the food system framework and place key challenges and bottlenecks to create a visual map of the problems. This methodology has been used effectively in both in person (Bangladesh) and online trainings (Vietnam and South Africa as part of another project). Participants of the workshop were positive about the activity of mapping the Vietnamese food system, with $88 \%$ of participants reporting it increased there understanding of the Vietnamese Food System a lot or significantly.

Material in the tool guide can be too theoretical. More grounding with practical examples would help. While there are very short (1-2 sentence) examples, perhaps links to worked case study or more detail would allow those with less familiarity with the tool to implement some of the activities. For example, one participant noted "[there is a] need detail guidance with real examples for others who are not work in related fields. The detail guide will help to apply the tool in reality feasibility," a sentiment that was echoed by other respondents.

In the Iceberg Model activity, a lack of examples may mean very large challenges are chosen, often which may have many underlying patterns and causes. This lack of specificity can mean that the outcomes of the workshop are more theoretical and not practical or specific enough. The activities can be find-tuned, and should be more grounded in the specific realities.

Perhaps a broader reflection on food systems work and training is that it can be hard to get all relevant stakeholders in the training. Often the majority of participants focus on issues of agriculture or improving consumer awareness about nutrition issues. In Vietnam none of the participants came from the private sector or worked on issues of transport, storage or processing. One participant suggested that we "need to train to others, such as companies [and] food traders". This "missing middle" is responsible for $30-40 \%$ of the costs and added value in the value chain, but is often missing in the overall discussions around nutrition and food security (Rearden, 2015). Raneri et al. also note that key developments in terms of processing, distribution and transport in Vietnam focus on foods for the export market, which could explain an overall lower level of discussion about these issues from a group focused on domestic food supply (2019).

Finally, labeling system archetypes is highly academic, hard to explain in a practical setting and may not always help define better solutions. In some ways forcing a specific definition on a complex problem may oversimplify and loose some of the systems connections. 


\section{Next Steps and Ways Forward}

Vietnamese Platform Members: would like to work together more and have more regular exchanges between those working on food system issues. Based on the outcomes of the Food Systems Dialogues and the New Policy platform members are interested in working in a more integrated way and adopt some of the ideas around food systems thinking that were discussed.

Food System Decision Support Tool: some of the suggestions for improvements will be communicated especially the idea of presenting more specific case studies. The tool, and modifications will also be used with other groups in additional setting, both to increase awareness of food systems thinking and to further develop and refine the tool. 


\section{References}

Herens, M., Pittore, K, Oosterveer, P. Forthcoming. Multistakeholder platforms; food system governance; food system transformation; healthier diets. Global Food Security

Posthumus, H., J.M. Bosselaar, H. Brouwer. 2021. The food system decision support tool - a toolbox for food system analysis. Wageningen University \& Research and KIT Royal Tropical Institute. https://edepot.wur.nl/541410.

Raneri Jessica E., Kennedy, Gina, Nguyen, Trang, Wertheim-Heck, Sigrid, Do, Ha; Nguyen, Phuong Hong, et al. 2019. Determining key research areas for healthier diets and sustainable food systems in Viet Nam. IFPRI Discussion Paper 1872. Washington, DC: International Food Policy Research Institute (IFPRI). https://doi.org/10.2499/p15738coll2.133433

Reardon, Thomas. 2015. The hidden middle: The quiet revolution in the midstream of agrifood value chains in developing countries. Oxford Review of Economic Policy vol 31.DOI:

10.1093/oxrep/grv011 
Wageningen Centre for Development Innovation

Wageningen University \& Research P.O. Box 88

6700 AB Wageningen

The Netherlands

T +31 (0)317486800

www.wur.eu/cdi

Report WCDI-21-183
Wageningen Centre for Development Innovation supports value creation by strengthening capacities for sustainable development. As the international expertise and capacity building institute of Wageningen University \& Research we bring knowledge into action, with the aim to explore the potential of nature to improve the quality of life. With approximately 30 locations, 6,800 members (6,000 fte) of staff and 12,900 students, Wageningen University \& Research is a world leader in its domain. An integral way of working, and cooperation between the exact sciences and the technological and social disciplines are key to its approach. 



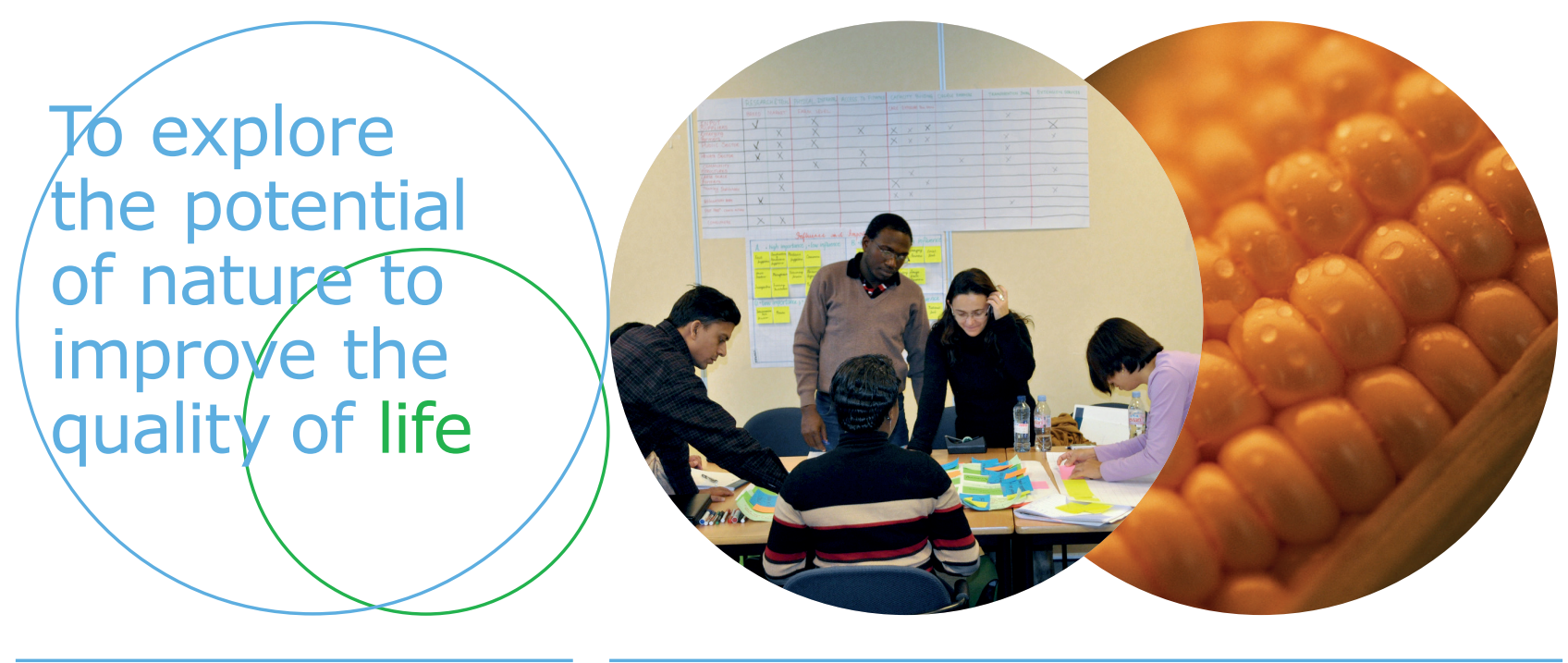

Wageningen Centre for Development Innovation Wageningen University \& Research P.O. Box 88 $6700 \mathrm{AB}$ Wageningen The Netherlands $\mathrm{T}+31$ (o)317 4868 oo www.wur.eu/cdi

Report WCDI-21-183
Wageningen Centre for Development Innovation supports value creation by strengthening capacities for sustainable development. As the international expertise and capacity building institute of Wageningen University \& Research we bring knowledge into action, with the aim to explore the potential of nature to improve the quality of life. With approximately 30 locations, 6,800 members (6,000 fte) of staff and 12,900 students, Wageningen University \& Research is a world leader in its domain. An integral way of working, and cooperation between the exact sciences and the technological and social disciplines are key to its approach. 